BMJ Open

Diabetes

Research

$\&$ Care

\title{
Impact of Ramadan fasting on glucose levels in women with gestational diabetes mellitus treated with diet alone or diet plus metformin: a continuous glucose monitoring study
}

\author{
Bachar O Afandi, ${ }^{1}$ Mohamed M Hassanein, ${ }^{2}$ Lina M Majd, ${ }^{1}$ Nico J D Nagelkerke ${ }^{3}$
}

To cite: Afandi BO, Hassanein MM, Majd LM, et al. Impact of Ramadan fasting on glucose levels in women with gestational diabetes mellitus treated with diet alone or diet plus metformin: a continuous glucose monitoring study. BMJ Open Diab Res Care 2017;5:e000470. doi:10.1136/ bmjdrc-2017-000470

Received 4 September 2017 Revised 6 November 2017 Accepted 18 November 2017

\section{(a) CrossMark}

${ }^{1}$ Endocrine Diabetes Center, Tawam Hospital/SEHA, Al Ain, Abu Dhabi, UAE

${ }^{2}$ Department of Endocrine, Dubai Hospital, DHA, Dubai, Dubai, UAE

${ }^{3}$ Medicine, Institute of Public Health, UAE University, Al Ain, Abu Dhabi, UAE

Correspondence to Dr Bachar 0 Afandi, Tawam Hospital; bafandi@seha.ae

\section{ABSTRACT}

Objective Women with gestational diabetes mellitus (GDM) are categorized as at high risk for adverse events during Ramadan fasting. However, this is largely based on clinical opinion. In this study, we shed some light on what happens to glucose levels during Ramadan fasting. Methods This is a prospective observational study. A total of 32 patients with GDM were recruited; 10 patients, treated with diet only (group 1), to observe their glucose levels before fasting and 22 patients who insisted on fasting the month of Ramadan, 13 treated with diet only (group 2) and nine treated with diet plus metformin $500 \mathrm{mg}$ twice daily (group 3), to evaluate their glucose levels during fasting. Interstitial glucose was monitored in all by using the iPro2 Professional continuous glucose monitoring (CGM) system.

Results Mean glucose level was $116 \pm 21 \mathrm{mg} / \mathrm{dL}$ $(6.16 \pm 1.16 \mathrm{mmol} / \mathrm{L}), 106 \pm 9 \mathrm{mg} / \mathrm{dL}(5.88 \pm 0.49 \mathrm{mmol} / \mathrm{L})$ and $99 \pm 7 \mathrm{mg} / \mathrm{dL}(5.49 \pm 0.34 \mathrm{mmol} / \mathrm{L})$ in groups 1,2 and 3 , respectively. Patients in group 1 had the lowest rate of hypoglycemia $(50 \%)$, followed by patients in group 2 $(60 \%)$, whereas patients in group 3 had the highest rate of hypoglycemia $(78 \%)$.

Conclusions CGM data indicates that Ramadan fasting in women with GDM treated with diet alone or with diet plus metformin was associated with lower mean glucose levels and higher rates of hypoglycemia when compared with non-fasting glucose levels. Women with GDM should be advised against fasting during Ramadan until further data is available.

\section{INTRODUCTION}

Diabetes is a growing health problem particularly in regions with a high Muslim population, such as South East Asia, Africa and the Middle East where the estimated 150 million Muslims with diabetes are expected to double in number by the year $2040 .{ }^{1}$

Ramadan fasting is one of the five main pillars of Islam. CREED study reported that $63.6 \%$ of people with type 2 diabetes fasted every day of Ramadan, while $94 \%$ fasted over 15 days of Ramadan. ${ }^{2}$ Fasting during Ramadan

\section{Significance of this study}

What is already known about this subject?

- The vast majority of Muslim women with gestational diabetes opt to fast in the month of Ramadan despite medical/religious advice not to do so.

- Most of the medical recommendations are based on expert opinion due to the paucity of clinical studies in this field.

What are the new findings?

- Our data suggest that Ramadan fasting increases the risk of hypoglycemia in women with GDM treated with diet alone or with diet \pm metformin.

- The impact of metformin on the glucose changes compared with diet only is of great clinical interest. It was associated with reduced risk of hyperglycemia and lower rate of severe hypoglycemia, however, with an increased risk of mild-moderate hypoglycemia when compared with diet alone during fasting.

How might these results change the focus of research or clinical practice?

- The data is an important step in risk quantification for women with GDM wishing to fast Ramadan.

- Women with GDM should be advised against fasting during Ramadan until further data is available.

- Continuous glucose monitoring could be of good value for understanding the blood glucose changes in patients with GDM treated with diet alone or with diet \pm metformin pre-Ramadan and during Ramadan fasting.

implies no intake of food or drink, including any oral medication, from dawn to sunset. In the year 2017, Ramadan started in May, where fasting hours in most countries lasted between 15 and 19 hours and in many countries also associated with hot weather. ${ }^{3}$ The physiological impact of changes in eating and sleep pattern during Ramadan are of 
particular concern for people with medical conditions such as diabetes. ${ }^{4}$

While Ramadan fasting is obligatory to all healthy adult Muslims, exemptions exist for many including women during pregnancy as well as for those with medical illness. ${ }^{4}$ Nevertheless, many studies have shown that the majority of healthy pregnant women opt to fast despite the burden of fasting while pregnant..$^{5-8}$ Some studies suggest that fasting for less than 15 hours is metabolically similar to an overnight fast for healthy pregnant woman. ${ }^{9}$ While ketonemia and hypoglycemia frequently occur with prolonged fasting, the overall evidence does not suggest that fasting adversely affects the infant. ${ }^{579-12}$ Furthermore, many studies on healthy women fasting during Ramadan have not demonstrated any significant impact of fasting on markers of infant well-being. ${ }^{11} 12$

In contrast, due to the potential risk of hypoglycemia, hyperglycemia, ketoacidosis, as well as dehydration and thrombosis, various diabetes and Ramadan guidelines have recommended that some people with diabetes, including all pregnant women with diabetes or gestational diabetes mellitus (GDM), should not fast due to the potential high risk on their health. ${ }^{13-17}$ However, this seems not to be well enforced by healthcare professionals and many pregnant women with diabetes are not clear whether to fast or not. ${ }^{18}$

It is important to note that categorizing women with GDM as at too high risk for adverse events during Ramadan fasting is largely based on clinical opinion rather than on empirical evidence due to the paucity of studies done in pregnant women with GDM or diabetes during Ramadan fasting, yet. A study in Saudi Arabia reported better glycemic control without adversely increasing the risk of hypoglycemia in those who fasted.$^{19}$ Improvement in fasting blood more importantly, postprandial blood glucose (BG) level, was shown in Hyperglycemia and Adverse Pregnancy Outcome (HAPO) study to correlate with pregnancy outcomes in women with GDM. ${ }^{20}$

While the evidence for an impact of hyperglycemia on pregnancy outcomes seems to be strong, evidence of harm due to hypoglycemia in pregnancy seems to be more difficult to find. Indeed, Yogev et al have shown that pregnant women seem to have up to $20 \%$ lower BG level than non-pregnant women without having symptoms of hypoglycemia. ${ }^{21}$ This is further supported by continuous glucose monitoring (CGM) study comparing glucose level in non-pregnant to those in pregnant women. Surprisingly, this study showed that blood levels below $60 \mathrm{mg}$ / $\mathrm{dL}$ were frequently observed in pregnancy, both among non-diabetics and those with gestational diabetes. ${ }^{22}$ Such levels of hypoglycemia were not seen in non-pregnant women. ${ }^{22}$

During pregnancy, treatment guidelines recommend BG targets to be well controlled, focusing on avoiding hyperglycemia both during fasting and postprandial, ${ }^{23}$ aiming at the following BG levels:

- fasting $\leq 95 \mathrm{mg} / \mathrm{dL}(5.3 \mathrm{mmol} / \mathrm{L})$ and either

- 1 hour postprandial $\leq 140 \mathrm{mg} / \mathrm{dL}(7.8 \mathrm{mmol} / \mathrm{L})$ or
2 hour postprandial $\leq 120 \mathrm{mg} / \mathrm{dL}(6.7 \mathrm{mmol} / \mathrm{L})$.

To achieve such tight glycemic control, women with gestational diabetes are recommended to self-monitor BG (SMBG) levels prebreakfast, post meals and whenever they feel symptoms of hypoglycemia or hyperglycemia. A recently published study, however, indicated that the actual frequency of monitoring in women with GDM was suboptimal and could be linked to poor pregnancy outcomes. ${ }^{24}$

CGM in routine care of GDM is not recommended. However, CGM could be a useful tool to add to our understanding of the impact of Ramadan fasting on glucose levels in women with GDM and ultimately lease to improve glycemic control.

\section{METHODS}

This is a prospective observational study done at Tawam Hospital Diabetes Center, Al-Ain city, UAE. The study was originally designed as an exploratory pilot study and the accurate calculation of sample size was not feasible due to paucity of data in the field. A total of 32 patients with GDM treated with diet \pm metformin who insisted on fasting during the lunar month of Ramadan 2017 were recruited. All participants provided written consent to participate. Before the month of Ramadan, all patients were counseled by a multidisciplinary team including endocrinologist, diabetes educators and nutritionists. They were all provided with one to one education to cover all aspects of diabetes in pregnancy as well as Ramadan focused advice. Postdiagnosis with GDM, all patients are initiated on diet \pm metformin or insulin according to their BG profile and/or patient preference. In our study, we report on patients treated with diet \pm metformin. All patients consented to wear the iPro2 Professional CGM device for a minimum of 3 days. In addition, and in order to calibrate the CGM device, patients were instructed to check their BG using a glucose meter a minimum of three, preferably six, times daily as the data of the CGM were blinded to the patient. Patients were explicitly instructed to include the late fasting hours of the day (16:00-19:00) as well as 1 hour after the two main meals (Iftar and Sohour). Hyperglycemia was defined as glucose level of more than $140 \mathrm{mg} / \mathrm{dL}(7.8 \mathrm{mmol} / \mathrm{L})$ and hypoglycemia was defined as glucose level below $70 \mathrm{mg}$ / $\mathrm{dL}(3.9 \mathrm{mmol} / \mathrm{L})$. Severity of hypoglycemia was classified as mild, moderate or severe when glucose levels were $60-69 \mathrm{mg} / \mathrm{dL}(3.30-3.85 \mathrm{mmol} / \mathrm{L}), 50-59 \mathrm{mg} / \mathrm{dL}$ $(2.80 \pm 3.25 \mathrm{mmol} / \mathrm{L})$, less than $50 \mathrm{mg} / \mathrm{dL}(2.80 \mathrm{mmol} / \mathrm{L})$, respectively.

The data was saved in MS Excel 2010, then uploaded to IBM SPSS V.20. For data analysis, we used descriptive analysis.

\section{RESULTS}

Ramadan 2017 started on 26 May and ended in the evening of 24June, and fasting hours started from around 04:00 am and ended around 07:00 pm. Out of 36 screened 
Table 1 Rates of normoglycemia, hyperglycemia and hypoglycemia in patients' groups

\begin{tabular}{llll}
\hline Group and treatment & Pre-Ramadan diet & Ramadan diet & Ramadan diet and metformin \\
\hline Number of patients & 10 & 13 & 9 \\
\hline $\begin{array}{l}\text { Total glucose readings } \\
\text { Mean glucose } \pm \text { SD }\end{array}$ & 8323 & 19411 & 14076 \\
& $\begin{array}{l}116 \mathrm{mg} / \\
\mathrm{dL} \pm 21(6.16 \pm 1.16 \mathrm{mmol} / \mathrm{L})\end{array}$ & $\begin{array}{l}106 \mathrm{mg} / \mathrm{dL} \pm 9(5.88 \pm 0.49 \mathrm{mmol} / \mathrm{L}) \\
\mathrm{dL} \pm 7(5.49 \pm 0.34 \mathrm{mmol} / \mathrm{L})\end{array}$ & $90.2 \% \pm 6.2 \%$ \\
$\begin{array}{l}\text { Per cent of time glucose level in } \\
70-140 \mathrm{mg} / \mathrm{dL}(7.7-10 \mathrm{mmol} / \mathrm{L}) \pm \mathrm{SD}\end{array}$ & $78.6 \% \pm 7.1 \%$ & $89 \% \pm 6.6 \%$ & $4.15 \% \pm 2.77 \%$ \\
$\begin{array}{l}\text { Per cent of time glucose level } \\
>140 \mathrm{mg} / \mathrm{dL}(7.7 \mathrm{mmol} / \mathrm{L}) \pm \mathrm{SD}\end{array}$ & $19.0 \% \pm 22 \%$ & $7.18 \% \pm 6.3 \%$ & $5.66 \% \pm 4.74 \%$ \\
$\begin{array}{l}\text { Per cent of time glucose } \\
\text { level }<70 \mathrm{mg} / \mathrm{dL}(3.88 \mathrm{mmol} / \mathrm{L} \pm \mathrm{SD}\end{array}$ & $2.71 \% \pm 3.86 \%$ & $3.76 \% \pm 4.99 \%$ & \\
\hline
\end{tabular}

patients, three refused participation and one was excluded because of misdiagnosis. A total of 32 patients participated in the study. Mean age $32.9 \pm 3$, prepregnancy body mass index (BMI) of $29.5 \pm 2 \mathrm{~kg} / \mathrm{m}^{2}$ and parity of $2.78(0-10)$. Personal history of GDM was confirmed in 15 patients $(47 \%)$ and family history of diabetes mellitus was present in 21 patients $(66 \%)$. Patients were divided into three groups: group 1 (10 patients) on diet only, monitored before Ramadan, group 2 (13 patients) on diet only, monitored during Ramadan fasting, and group 3 (nine patients) treated with diet plus metformin $500 \mathrm{mg}$ twice daily, monitored during Ramadan fasting. Mean monitoring periods were 3.0, 5.2 and 5.5 days and total glucose readings were 8323, 19411 and 14076 for groups 1, 2 and 3, respectively. Patients in the study monitored their BG using the glucose reading meter on average of 3.4 readings/patient/day. All patients completed their fast throughout the monitoring period with no reports of adverse events or hospital admissions.

Mean glucose level was $116 \pm 21 \mathrm{mg} / \mathrm{dL}$ $(6.16 \pm 1.16 \mathrm{mmol} / \mathrm{L}), 106 \pm 9 \mathrm{mg} / \mathrm{dL}(5.88 \pm 0.49 \mathrm{mmol} / \mathrm{L})$ and $99 \pm 7 \mathrm{mg} / \mathrm{dL}(5.49 \pm 0.34 \mathrm{mmol} / \mathrm{L})$ in groups 1,2 and 3 , respectively.

Patients in group 1 (pre-Ramadan) had the highest incidence of hyperglycemia and the lowest rate of hypoglycemia, whereas patients in group 3 (on diet plus metformin fasting) had the highest rate of hypoglycemia with the highest rate of normoglycemia and lowest rate in hyperglycemia (table 1).

Analysis of postprandial hyperglycemia revealed that glucose levels of more than $180 \mathrm{mg} / \mathrm{dL}(10 \mathrm{mmol} / \mathrm{L})$ occurred during $32 \%, 23 \%$ and $5 \%$ of hyperglycemic

\begin{tabular}{lll}
\hline Table 2 & Severity of hyperglycemia \\
& $\begin{array}{l}\text { Glucose level } \\
\text { between } 140 \text { and } 180 \\
\text { mg/dL (7.7-10 } \mathbf{m m o l} / \mathrm{L}) \\
(\%)\end{array}$ & $\begin{array}{l}\text { Glucose level } \\
>180 \mathrm{mg} / \mathrm{dL} \\
(\mathbf{1 0} \mathrm{mmol} / \mathrm{L})(\%)\end{array}$ \\
\hline Group 1 & 68 & 32 \\
Group 2 & 77 & 23 \\
Group 3 & 95 & 5 \\
\hline
\end{tabular}

CGM observations in groups 1, 2 and 3, respectively (table 2).

Further analysis of hypoglycemia revealed that hypoglycemia occurred at least once in 50\%, 60\% and $78 \%$ of patients in groups 1, 2 and 3, respectively. While $71 \%$ of hypoglycemia before Ramadan was in the fasting (prebreakfast) and 29\% was in the prandial states; however, $100 \%$ of hypoglycemic episodes in Ramadan were encountered in the late fasting hours of the day (16:00-19:00). The severity of hypoglycemia shows that the incidence of severe hypoglycemia, a glucose level of less than $50 \mathrm{mg} / \mathrm{dL}(2.80 \mathrm{mmol} / \mathrm{L})$, was $0 \%, 23 \%$ and $4 \%$ in groups 1, 2 and 3, respectively (table 3 ).

\section{DISCUSSION}

Our study has many important clinical implications despite the fact that these groups may not have been totally comparable as allocation was not random and indeed; the aim of the study was to have a better understanding of changes in BG levels during fasting and non-fasting periods for women with GDM. As mentioned above, many Muslim women with GDM insist on fasting the month of Ramadan despite medical and religious recommendations not to do so. ${ }^{5-8}$ The CGM data in this study shed light on what happens to glucose levels during Ramadan fasting compared with pre-Ramadan. In our study, the glucose levels above $140 \mathrm{mg} / \mathrm{dL}$ were considered as high for educational purposes and those above $180 \mathrm{mg} / \mathrm{dL}$ were considered very high. Our data indicate that glucose levels were better in those women with GDM fasting in Ramadan than pre-Ramadan whether they were treated with diet plus metformin or diet only. Indeed, the average difference between the pre-Ramadan and during Ramadan glucose level of group 3 who were treated with diet and metformin was over $17 \mathrm{mg} / \mathrm{dL}$. Furthermore, this group had the highest rate of normoglycemia in the study $(90.2 \%)$. This result is similar to what was observed previously in a study from Saudi Arabia where it was noted that women with GDM who fasted during Ramadan had a better glycemic control. ${ }^{19}$ Nevertheless, in our opinion, women with GDM should be advised against fasting until further studies on benefits and risks are conducted. 
Table 3 Frequency and severity of hypoglycemia

\begin{tabular}{|c|c|c|c|}
\hline $\begin{array}{l}\text { Frequency of glucose } \\
\text { level } \\
<70 \mathrm{mg} / \mathrm{dL} \\
\text { (<3.9 } \mathrm{mmol} / \mathrm{L})(\%)\end{array}$ & $\begin{array}{l}\text { Mild hypoglycemia } \\
\text { glucose level } \\
60-69 \mathrm{mg} / \mathrm{dL} \\
(3.30-3.85 \mathrm{mmol} / \mathrm{L})(\%)\end{array}$ & $\begin{array}{l}\text { Moderate hypoglycemia } \\
\text { glucose level } \\
50-59 \mathrm{mg} / \mathrm{dL} \\
(2.80 \pm 3.25 \mathrm{mmol} / \mathrm{L})(\%)\end{array}$ & $\begin{array}{l}\text { Severe hypoglycemia } \\
\text { glucose level } \\
<50 \mathrm{mg} / \mathrm{dL} \\
\text { (<2.80 mmol/L) (\%) }\end{array}$ \\
\hline 50 & 92 & 8 & 0 \\
\hline 60 & 58 & 19 & 23 \\
\hline 78 & 74 & 22 & 4 \\
\hline
\end{tabular}

The frequency and the severity of hypoglycemia in pregnant women is clinically important. Previous studies have indicated that BG levels in pregnant women could be up to $20 \%$ lower than those of non-pregnant women regardless of their glycemic status. ${ }^{21}$ Indeed, previous studies in pregnant women labeled BG levels $<60$ to be mild hypoglycemia and showed that this is not an uncommon occurrence regardless of their glycemic status. ${ }^{22}$ Furthermore, in another CGM study including 10 healthy pregnant women, hypoglycemia was also noted. ${ }^{24}$ Guided by these data, we grouped hypoglycemia by severity, as mild (69-60 mg/dL), moderate (59-50 mg/dL) or severe $(<50 \mathrm{mg} / \mathrm{dL})$. In our study, utilizing CGM data, hypoglycemia was seen in all groups including $50 \%$ of patients in group 1 (pre-Ramadan) who were treated with diet only. Furthermore, our data showed that about $8 \%$ of the hypoglycemic episodes in group 1 were below $60 \mathrm{mg}$ / $\mathrm{dL}$; however, there were no episodes in this group with BG $<50 \mathrm{mg} / \mathrm{dL}$. These results are highly important as they corroborated previous studies in healthy pregnant women and may question the cut-off for the definition of hypoglycemia during pregnancy.

Contrary to what was observed in the Saudi study, ${ }^{19}$ our data suggest that Ramadan fasting increases the rate of all levels of hypoglycemia as patients in groups 2 and 3 , respectively, had $60 \%$ and $78 \%$ incidence of hypoglycemia compared with the $50 \%$ noted in group 1 (pre-Ramadan). More importantly, rates of severe hypoglycemia were much higher in patients in group 2 (23\%) and group $3(4 \%)$ who were fasting in the month of Ramadan, while there was no severe hypoglycemia in group 1 patients who were not fasting. The difference in rates of hypoglycemia between our study and the Saudi study could be due to our use of CGM while the Saudi study used SMBG. It is noteworthy that the hypoglycemic episodes detected during our study were all asymptomatic, and the implications of this should be further explored.

The value of CGM in women with GDM is another interesting point. In this study, the CGM data were blinded as the main objective was to understand the glucose changes that occur in GDM women during pre-Ramadan and Ramadan. In light of these data, it would be interesting to see the impact of unblinded CGM on the behaviour and on the overall glucose changes of women with GDM during fasting in Ramadan. The value of CGM was stressed on for monitoring gestational glucose variability including beyond what is simply observed by HbAlc. ${ }^{24}$
Indeed, in this study, BG fluctuations were observed in healthy pregnant women, those with GDM as well as pregnant women with type 1 diabetes. ${ }^{24}$ Our patients were using SMBG during the study and the frequency of their SMBG test averaged 3.4 tests/daily. This is in line with recent concerns about the low frequency of SMBG monitoring by women with GDM and its implications for the outcome of the pregnancy. ${ }^{25}$

Metformin use in GDM is not universally accepted as many guidelines recommend management with insulin as the gold standard of care. However, many clinicians opt for metformin as many of our patients with GDM are reluctant to start insulin therapy. The glucose levels observed in group 3 treated with diet and metformin during Ramadan fasting in GDM deserves further study, as it seems that they had the best rate of $\mathrm{BG}$ where their mean glucose level was $99 \pm 7 \mathrm{mg} / \mathrm{dL}(5.49 \pm 0.34 \mathrm{mmol} / \mathrm{L})$ compared with group 2 who fasted and were treated with diet only and had a mean $\mathrm{BG}$ of $106 \pm 9 \mathrm{mg} / \mathrm{dL}$ $(5.88 \pm 0.49 \mathrm{mmol} / \mathrm{L})$. While the overall rate of hypoglycemia in group 3 was higher than group 1 or 2 , this occurred with lower rates of severe hypoglycemia than group 2 ( $4 \%$ vs $23 \%$ ).

A limitation of our study was its small size, it being designed as an exploratory study only and thus limited statistical power. More limitations include the lack of reporting adverse maternal and neonatal outcomes. Furthermore, the size of the sample did not allow analysis of other potentially confounding factors such as age, parity, BMI, personal and family history. Nevertheless, the results of our study are highly informative and call for a larger multicentre study to verify the significance of this clinically important data and to also look into pregnancy and neonatal outcomes of women with GDM insisting on Ramadan fasting.

\section{CONCLUSIONS}

CGM could be of good value for monitoring glucose in patients with GDM during Ramadan fasting as it allows better understanding of rates of hypo/hyperglycemia during fasting. Furthermore, data indicates that hypoglycemia can occur in women with GDM regardless of the type of treatment they are on and indeed, independent from their fasting status. Ramadan fasting in women with GDM treated with diet alone or with diet plus metformin was associated with lower mean glucose levels but higher 
rates of hypoglycemia when compared with non-fasting glucose levels. Women with GDM should be advised against fasting during Ramadan until further data is available.

Contributors BOA planned and submitted the study for approval, researched data, wrote and edited the manuscript. MH planned the study, researched data, wrote and edited the manuscript. LM recruited and followed patients, obtained consents, contributed to discussion. NN analysed the data and edited the manuscript. BA takes full responsibility for the work. The authors have no relevant conflict of interest to disclose.

Funding This research received no specific grant from any funding agency in the public, commercial or not-for-profit sectors.

Competing interests None declared.

Ethics approval Al-Ain Medical District Human Research and Ethics Committee (CRD517/17 Protocol N0 17-46).

Provenance and peer review Not commissioned; externally peer reviewed. Data sharing statement This material has not been published previously and is not under consideration for publication elsewhere.

Open Access This is an Open Access article distributed in accordance with the Creative Commons Attribution Non Commercial (CC BY-NC 4.0) license, which permits others to distribute, remix, adapt, build upon this work non-commercially, and license their derivative works on different terms, provided the original work is properly cited and the use is non-commercial. See: http://creativecommons.org/ licenses/by-nc/4.0/

(c) Article author(s) (or their employer(s) unless otherwise stated in the text of the article) 2017. All rights reserved. No commercial use is permitted unless otherwise expressly granted.

\section{REFERENCES}

1. International diabetes federation. IDF diabetes atlas. 8th edn, 2015. http://www.diabetesatlas.org/

2. Babineaux SM, Toaima D, Boye KS, et al. Multi-country retrospective observational study of the management and outcomes of patients with type 2 diabetes during Ramadan in 2010 (CREED). Diabet Med 2015;32:819-28.

3. CII Radio. Longest and shortest fasting times around the world Ramadan 2017. https://ciiradio.com/2017/05/26/longest-andshortest-fasting-times-around-the-world-ramadan2017/

4. International Diabetes Federation. Diabetes and ramadan: practica guidelines. Brussels, Belgium: International Diabetes Federation. www.idf.org/guidelines/diabetes-in-ramadan and www.daralliance. org2016

5. Prentice AM, Prentice A, Lamb WH, et al. Metabolic consequences of fasting during Ramadan in pregnant and lactating women. Hum Nutr Clin Nutr 1983;37:283-94.
6. Fowler $\mathrm{H}$, Griffin $\mathrm{E}$, Lawton $\mathrm{F}$, et al. Antenatal attendance and fasting of pregnant muslims during Ramadan. Br J Obstet Gynaecol 1990;97:861-2

7. Malhotra A, Scott PH, Scott J, et al. Metabolic changes in asian muslim pregnant mothers observing the Ramadan fast in Britain. $\mathrm{Br}$ J Nutr 1989;61:663-72.

8. Reeves J. Pregnancy and fasting during Ramadan. $B M J$ 1992;304:843-4.

9. Robinson T, Raisler J. "Each one is a doctor for herself": ramadan fasting among pregnant Muslim women in the United States. Ethn Dis 2005;15(Suppl 1):99-103.

10. Kaplan M, Eidelman Al, Aboulafia Y. Fasting and the precipitation of labor. The yom kippur effect. JAMA 1983;250:1317-8.

11. Cross $\mathrm{JH}$, Eminson J, Wharton BA. Ramadan and birth weight at full term in Asian Moslem pregnant women in Birmingham. Arch Dis Child 1990;65:1053-6.

12. Hefni M, Fikry SAH, Abdalazim M, et al. Fasting in Ramadan and preterm labour. Saudi Med J 1993;14:130-2.

13. Hui $\mathrm{E}$, Bravis $\mathrm{V}$, Hassanein $\mathrm{M}$, et al. Management of people with diabetes wanting to fast during Ramadan. BMJ 2010;340:c3053-1411.

14. Al-Arouj M, Assaad-Khalil S, Buse J, et al. Recommendations for management of diabetes during Ramadan: update 2010. Diabetes Care 2010;33:1895-902.

15. Ibrahim M, Abu Al Magd M, Annabi FA, et al. Recommendations for management of diabetes during Ramadan: update 2015. BMJ Open Diabetes Res Care 2015;3:e000108.

16. Hassanein M, Al-Arouj M, Hamdy O, et al. Diabetes and Ramadan: practical guidelines. Diabetes Res Clin Pract 2017;126:303-16.

17. Beshyah SA. Fasting during the month of ramadan for people with diabetes: medicine and Fiqh united at last. Ibnosina $J$ Med Biomed Sc 2009;1:58-60.

18. Hui $\mathrm{E}$, Reddy M, Bravis V, et al. Fasting among pregnant women with diabetes during Ramadan. Int J Clin Pract 2012;66(9):910-1.

19. Sulimani $R$, Anani M, Khatib $O$, et al. Should diabetic pregnant mothers fast during Ramadan? Saudi Med J 1998;19:50-1.

20. Metzger BE, Lowe LP, Dyer AR, et al. HAPO study cooperative research group. Hyperglycemia.

21. Yogev $\mathrm{Y}$, Ben-Haroush A, Chen R, et al. Diurnal glycemic profile in obese and normal weight nondiabetic pregnant women. $A m \mathrm{~J}$ Obstet Gynecol 2004;191:949-53.

22. Mazze R, Yogev Y, Langer O. Measuring glucose exposure and variability using continuous glucose monitoring in normal and abnormal glucose metabolism in pregnancy. J Matern Fetal Neonatal Med 2012;25:1171-5.

23. Metzger BE, Buchanan TA, Coustan DR, et al. Summary and recommendations of the fifth international workshop-conference on gestational diabetes mellitus. Diabetes Care 2007;30(Suppl. 2):S251-60

24. Dalfrà MG, Chilelli NC, Di Cianni G, et al. Glucose fluctuations during gestation: an additional tool for monitoring pregnancy complicated by diabetes. Int J Endocrinol 2013;2013:1-8.

25. Cosson E, Baz B, Gary F, et al. Poor reliability and poor adherence to self-monitoring of blood glucose are common in women with gestational diabetes mellitus and may be associated with poor pregnancy outcomes. Diabetes Care 2017;40:1181-6. 